\title{
O que se Traz para a Vida e o que a Vida nos Traz: Uma Análise da Equação Etiológica proposta por Freud à Luz das Neurociências
}

\section{What we Bring to Life and what Life Brings to Us: An Analysis of the Ethiological Equation proposed by Freud According to Neurosciences}

\author{
Monah Winograd ${ }^{a}$, Carlos A. Q. Coimbra ${ }^{b} \&$ J. Landeira-Fernandez* ${ }^{a} c$ \\ ${ }^{a}$ Pontificia Universidade Católica do Rio de Janeiro, Rio de Janeiro, Brasil \\ ${ }^{b}$ Museu de Astronomia, MAST/MCT, Rio de Janeiro, Brasil \\ 'Universidade Estácio de Sá, Rio de Janeiro, Brasil
}

\begin{abstract}
Resumo
O presente trabalho tem como objetivo discutir aspectos teóricos, clínicos e experimentais acerca da interação entre variáveis inatas e aprendidas com relação à origem e desenvolvimento de distúrbios emocionais. Apresentase inicialmente a equação etiológica proposta por Freud acerca das neuroses na virada do século XX e sua relação com a teoria da sedução. Apresentam-se também algumas evidências clínicas e experimentais que dão supor te à noção de equação etiológica. Estas evidências demonstram a importância de determinantes genéticos que regulam a atividade serotonérgica assim como a influência de eventos traumáticos que ocorrem dentro e fora do período crítico. A influência do ambiente, como por exemplo, o apoio social, pode também aliviar a expressão destes distúrbios emocionais. O trabalho busca também modelar matematicamente a equação etiológica através de uma regressão logística incorporando todos estes parâmetros.

Palavras-chave: Inato/adquirido; equação etiológica; neurose; depressão; teoria da evolução; período crítico; resiliência; Neuropsicanálise.
\end{abstract}

\begin{abstract}
The aim of this paper is to discuss theoretical issues as well as clinical and experimental evidences regarding the nature versus nurture debate of the origins and development of emotional disturbances. The etiological equation as proposed by Freud at the turn of the 20th century is presented. Clinical and experimental evidences, which support the notion of the etiological equation, are also presented. These evidences indicate the importance of the genetic makeup that regulates serotonergic activity as well as traumatic experiences that occur inside or outside the critical period. Environmental interactions, such as social support, can also relieve the expression of emotional dysfunction. A mathematical model of the etiological equation is presented through a logistic regression in which all these parameters are incorporated.

Keywords: Nurture/nature; etiologic equation; neurosis; depression; evolutionary theory; critical period; resilience; Neuropsychoanalysis.
\end{abstract}

O século XX foi um período importante para as ciências da saúde. A neuroanatomia e a neurofisiologia tiveram um rápido desenvolvimento e adquiriram grande maturidade acadêmica. A biologia molecular surgiu como uma nova ciência e adquiriu uma posição de extraordinário destaque entre as ciências modernas. Na metade do século $\mathrm{XX}$, surgiu a área interdisciplinar da neurociência com o propósito de investigar os mecanismos neurais subjacentes à atividade mental humana.
Um dos principais debates da neurociência em particular e das ciências humanas em geral é a dicotomia inato X aprendido no que se refere à condição saudável e patológica do funcionamento da atividade mental humana. Especificamente, as causas dos transtornos emocionais têm sido objeto de grande interesse e especulação. Por exemplo, os diferentes transtornos de ansiedade são conseqüências de uma predisposição genética ou surgem graças a formas particulares de relacionamento do sujeito com o seu meio? São as neuroses endógenas ou exógenas? São conseqüências da constituição do indivíduo ou produto de certas experiências traumáticas? São hereditárias ou adquiridas?

Para Freud, esta dicotomia era um falso problema, pois sublinhar um ou outro dos fatores em operação na etiologia das afecções psíquicas significava perceber apenas parte da verdade. Novas pesquisas acerca do desenvolvimento cerebral e sua relação com o meio ambiente têm permiti- 
do uma redescoberta das teorias psicanalíticas acerca da etiologia das doenças mentais. O propósito deste trabalho é o de apresentar a concepção psicanalítica acerca da origem e do desenvolvimento destas afecções psíquicas e contrastá-la com evidências experimentais advindas de diferentes áreas das neurociências. Pretende-se também modelar matematicamente a equação etiológica proposta por Freud através de uma regressão logística incorporando todos estes parâmetros.

\section{O Conceito de Genético na Época de Freud ${ }^{1}$}

Quando Freud desenvolveu suas elaborações sobre a etiologia das neuroses muito pouco se sabia acerca do funcionamento do cérebro e seus determinantes genéticos. Embora Gregor Mendel houvesse descoberto as primeiras leis da genética em 1865, estes trabalhos ficaram esquecidos até à virada do século XX, quando a biologia molecular de fato teve início. Entretanto, os mecanismos celulares envolvidos na expressão genética a partir da síntese de proteínas através do ácido desoxirribonucléico (ADN) só se tornaram claros a partir de 1953, quando James Watson e Francis Crick sugeriram a estrutura desta molécula. De modo que o conceito de genético, tal como utilizamos atualmente, é bem diferente do modo como era usado na época em que Freud desenvolveu suas teorias. Por exemplo, a utilização dos termos 'filogênese' (associados ao desenvolvimento de uma espécie) e 'ontogênese' (relacionados ao desenvolvimento de um indivíduo) em Freud não dizia respeito ao código genético da forma como entendemos hoje, mas sim, ao conceito de que o ser humano poderia herdar características filogenéticas de seus ancestrais, incluídas aquelas presentes na cultura, na linguagem, ou no desejo.

Este conceito lamarckista, que inclusive esteve presente em Darwin, permaneceu no meio acadêmico até 1930, data da publicação do livro "The genetical theory of natural selection". Neste livro, Ronald Aylmer Fisher confirma a associação entre o princípio darwiniano de seleção natural e o conceito mendeliano de hereditariedade através de análises publicadas em 1918 em seu magnífico artigo "The correlation between relatives on the supposition of Mendelian Inheritance" (Fisher, 1918). Neste artigo, Fisher demonstrou, através de técnicas de correlação, que a variabilidade de determinadas características poderiam ser explicadas pela idéia mendeliana de expressão multigênica de alelos dominantes e recessivos - ou seja, a palavra "genético" passou, ao longo das primeiras décadas do século $\mathrm{XX}$, a referir-se ao fato de certas características herdadas por um indivíduo estarem associadas exclusivamente às características genéticas de seus pais, independentemente de suas relações com o meio, como por exemplo, a cor dos olhos e a cor da pele (Yates \& Mather, 1963).

\footnotetext{
${ }^{1}$ A elaboração desta seção só foi possível graças à valiosa contribuição de um dos pareceristas ad hoc, ao qual os autores agradecem.
}

Apesar das transformações sofridas pelo conceito de 'genético', a idéia de uma interação entre processos filogenéticos e processos ontogenéticos sempre esteve presente nas mais diversas teorias que pretendiam explicar a interação do indivíduo com o seu meio, tanto relativamente à expressão de características funcionais, quanto patológicas. Assim, já na época de Freud, qualquer teoria a respeito da etiologia de uma patologia psíquica deveria levar em consideração sua fonte dupla, agindo em conjunto ou em separado: de um lado, experiências ou agentes nocivos oriundos do meio externo e, de outro lado, fatores endógenos (Sulloway, 1979).

\section{A Equação Etiológica}

Em 1895, discutindo com quem situava os fatores endógenos (hereditariedade) como causa principal e tratava as afecções neuróticas a partir desta perspectiva, Freud introduziu uma expressão da qual jamais abriu mão: equação etiológica (1895/1996a). Tal expressão sofreu modificações ao longo da obra de Freud, sobretudo quando ele deixou de ser neurologista para se tornar metapsicólogo. A despeito destas transformações, ela expressa um modelo no qual a origem e desenvolvimento das diferentes formas de neurose estaria relacionado com diferentes tipos de variáveis. Estas variáveis eram:

1. Pré-condição (Bedingung): fatores em cuja ausência o efeito nunca se produz, mas que são incapazes de gerálo por si mesmos, não importando qual seja a escala em que estejam presentes, pois falta a causa específica. São os fatores hereditários, causas necessárias duradouras e de difícil modificação.

2. Causa Específica (Spezifische Ursache): fatores presentes em todos os casos em que o efeito se dá e que, quando presente na quantidade ou intensidade requerida é suficiente para produzir o efeito, desde que as condições também sejam cumpridas. Também é causa necessária, mas sua entrada em ação é mais recente, o que a torna mais suscetível a alterações.

3. Causas Concorrentes ou Auxiliares (Konkurrierende Ursache): fatores que não estão necessariamente presentes todas as vezes, nem podem, qualquer que seja a sua escala de ação, produzir o efeito por si mesmos, mas que operam em conjunto com as condições e a causa específica para satisfazer a equação etiológica. São quaisquer perturbações "banais" como emoções intensas, susto, esgotamento físico etc.

4. Causa Precipitante ou Desencadeante (Veranlassung Oder Auslösende Ursache): a que aparece por último na equação, precedendo imediatamente a aparição do efeito. Sua natureza essencial é apenas esse fator temporal.

Dentre estes quatro tipos de variáveis, apenas duas são necessárias: a pré-condição e a causa específica. O fato de serem ambas necessárias, não significa que tenham a mesma natureza ou que operem da mesma maneira. Muito pelo contrário. Freud buscou identificar as manifestações de uma e de outra da seguinte forma: (a) a ocorrência de uma neurose depende de um fator quantitativo relacionado com a carga total sobre o sistema anímico ("sistema ner- 
voso», na época destas formulações) em proporção à sua capacidade de resistência. Tudo o que possa manter ou retrair esta variável abaixo de certo limite possui eficácia terapêutica, pois faz com que o resultado da equação etiológica fique abaixo de um limiar patológico. Por outro lado, pré-condição e causas específicas (as únicas necessárias) podem substituir-se uma à outra no que tange à quantidade, ou seja, o mesmo efeito acontece quando a etiologia específica é muito grave e a pré-condição é moderada, ou o contrário; (b) a dimensão ou o alcance de uma neurose depende, em primeira instância, da extensão da «carga hereditária». Ou seja, a hereditariedade funciona como um multiplicador representado na equação, uma espécie de amplificador da patologia; e (c) a forma que a neurose assumirá - de acordo com o modelo, o tipo de neurose que irá se expressar em um determinado indivíduo é determinado exclusivamente pelo fator etiológico específico.

A primeira especificação (o fator quantitativo) trazia em si a necessidade de Freud afirmar o método de tratamento que tinha inventado e que incidia sobre as causas específicas, mais suscetíveis à alterações do que os fatores hereditários porque mais recentes. A segunda e a terceira afirmações diferenciam as manifestações da hereditariedade e da causa específica no efeito produzido. A primeira é précondição, como uma quantidade já dada que multiplica o efeito da causa específica, sendo que uma pode substituir a outra neste aspecto quantitativo. A segunda, a causa específica, influi na escolha da neurose, ou seja, no tipo de afecção ocorrida, no por que desta e não de outra. Portanto, são dois problemas interconectados que Freud pretendia resolver: o da origem da neurose em geral e de cada neurose em particular. Embora um implique necessariamente o outro, são problemas diferentes. O primeiro pode ser alargado para a questão da própria constituição do psiquismo: o que importa na formação de um psiquismo, o hereditário ou o que foi adquirido mais recentemente?

No exemplo da tuberculose pulmonar (Freud, 1895/ 1996a), a infecção propriamente dita é o efeito; a predisposição da constituição orgânica dada, na maioria das vezes, hereditariamente é a pré-condição; o bacilo de Koch é a causa específica e qualquer coisa que provoque uma fragilidade, como emoções, infecções ou resfriados, funcionam como causa auxiliar. No caso das neuroses, o esquema é semelhante: a neurose é o efeito, a hereditariedade é a pré-condição e qualquer coisa banal, mas que fragiliza, como emoção intensa, horror, esgotamento psíquico por excesso de trabalho ou por doença, pode ser a causa auxiliar. Qual seria, então, a causa específica sem a qual a hereditariedade não produziria efeitos? Qual seria o bacilo de Koch da neurose?

\section{Da Teoria da Sedução à Noção de Séries Complementares}

O jovem médico tinha uma teoria a respeito: . . cada uma das grandes neuroses enumeradas ${ }^{2}$ tem por causa imediata uma perturbação particular da economia nervosa, e estas modificações patológicas fun- cionais registram como fonte comum a vida sexual do indivíduo, seja uma desordem da vida sexual atual, seja uns acontecimentos importantes da vida sexual passada. (Freud, 1896/1996b, p. 149).

Embora nesta citação Freud não diferenciasse neurose atual (desordem da vida sexual atual) de psiconeurose (acontecimento importante da vida sexual passada), ele sabia que creditar a ambas uma origem sexual não era novidade. O que distinguia sua teoria era a capacidade destas influências sexuais produzirem causas específicas e reconhecer sua ação em todos os casos de neurose. Esta era a sua famosa teoria do trauma ou teoria da sedução a qual abandonou pouco tempo depois. Em 21 de setembro de 1897, ele escreveu ao seu amigo Willhem Fliess (18581928) que não acreditava mais em sua "neurotica" por vários motivos. Primeiro, a dificuldade em fazer a análise remontar a um acontecimento real; segundo, a debandada dos pacientes; terceiro, a ausência do êxito completo esperado e a possibilidade de explicar os êxitos parciais de outro modo. Seu modelo necessitava de uma revisão profunda, embora a idéia de uma equação etiológica permanecesse como pressuposto fundamental de seu modo de compreender, mais do que a origem das afecções "patológicas", a constituição e o desenvolvimento do psiquismo humano em geral (Freud, 1897/1996c).

Em 1916 - em função da amarração de conceitos tais como recalcamento, pulsão e inconsciente, operada no ano anterior nos famosos artigos de metapsicologia - a equação etiológica de 1895 ganha uma complementação e assim se transforma. $\mathrm{Na} 22^{\mathrm{a}}$. das conferências introdutórias proferidas nos Estados Unidos, aparece pela primeira vez a noção de séries complementares (Freud, 1916-1917/1996f). A essa altura, já de posse dos conceitos de recalcamento, inconsciente e pulsão, a idéia de Freud era a de que seres humanos contraem uma neurose quando, por diversos motivos, lhes é retirada a possibilidade de satisfazer sua libido. Em outras palavras, a frustração da satisfação da libido estava presente em todos os casos de neurose, o que fazia dela uma causa específica na equação etiológica. Mas, como vimos, a causa específica só é capaz de produzir neurose se as condições estiverem cumpridas - causa específica e pré-condição operam em conjunto numa relação quantitativa.

Para que haja efeitos patógenos, é preciso que ocorra uma falência (Versagung), frustrando a única forma de satisfação de que o indivíduo é capaz. Se ele puder, por assim dizer, deslocar sua libido para novos objetos ou para alvos não sexuais (sublimação), possivelmente não neurotizará, embora o grau de libido insatisfeita que se possa suportar seja limitado. A plasticidade ou, ao contrário, a viscosidade libidinal pode ser maior ou menor conforme o caso, mas, em todos os indivíduos, há um limite a 
partir do qual a frustração da satisfação pode ter como efeito a regressão da libido a fases anteriores de seu desenvolvimento, determinada a partir das fixações libidinais ocorridas nas histórias individuais. Para Freud, é preciso que, além da constituição, certas exigências excessivas da vida estejam presentes para que uma neurose ocorra noutros termos, além da constituição individual, é necessária a concorrência de exigências da vida das quais o sujeito não consegue dar conta.

Porém, havia mais em jogo na etiologia das neuroses do que somente a impossibilidade de satisfação libidinal devido ao contexto ambiental, somada à plasticidade libidinal de cada indivíduo. Havia casos nos quais indivíduos até então saudáveis, neurotizavam repentinamente, sem que, em um determinando momento da vida do indivíduo, houvesse ocorrido uma exigência maior do que as usuais. Em tais casos, poder-se-ia facilmente identificar a ocorrência de um conflito psíquico, ou seja, a concorrência de moções pulsionais contraditórias à organização euóica.

Em 1915, retomando o conceito de pulsão, Freud a define como uma força de fonte corporal que exerce uma pressão constante, fazendo uma exigência de trabalho ao aparelho psíquico no sentido de sua satisfação e representada psiquicamente pela representação e pelo afeto. Se alguma moção pulsional revelar-se contraditória à organização euóica, então seu representante-representação (Vorstellungrepräsentant) pode ser recalcado e o afeto ligado a ele poderá, por exemplo, se vincular a outra representação, buscando novos caminhos para a satisfação da pulsão. A rigor, Freud identifica quatro destinos possíveis para a pulsão: (a) reversão ao seu oposto; (b) retorno sobre a própria pessoa; (c) recalcamento e (d) sublimação (Freud, 1915/1996d). Todos revelam caminhos para a satisfação e podem, de acordo com a sua intensidade, engendrar uma neurose.

O terceiro destes destinos mereceu considerações particulares, uma vez que Freud o considerava como a pedra angular de toda a sua teoria (Freud, 1915/1996e). Designado como o processo que visa manter no Inconsciente as representações ligadas às pulsões e cuja realização, produtora de prazer, afetaria o equilíbrio do funcionamento psíquico do indivíduo ao se tornar fonte de desprazer para parte do eu, o conceito de recalque sofreu modificações ao longo de toda a obra freudiana relativamente a sua definição e ao seu campo de ação, mas nunca deixou de ser a pedra fundamental, o pilar do edifício psicanalítico. Mecanismo presente em todos os indivíduos por ser constitutivo do Inconsciente, o recalcamento é exercido sobre as excitações internas de origem pulsional, cuja persistência provocaria um desprazer excessivo. Mas, o recalcamento de um representante da pulsão não é jamais definitivo, pois as representações recalcadas permanecem ativas no Inconsciente, sempre prontas a forçar sua reentrada no campo da consciência e, portanto, exigindo um gasto constante de energia para sustentar o recalque. Porém, em linhas muito gerais, as aspirações pulsionais conseguem imporse, fazendo certos rodeios para driblar o veto imposto pelo recalque, através de desfigurações e atenuações, ligando- se a outras representações vinculadas às que foram recalcadas, mas mais palatáveis à organização euóica consciente. Tais rodeios são os caminhos da formação de sintomas, os quais constituem uma satisfação substitutiva que se fez necessária pela falência do modo de satisfação anterior.

Nesta época (1915), o conflito psíquico era pensado como o resultado do confronto entre forças pulsionais sexuais e forças pulsionais auto-conservaticas, entre a sexualidade e o eu. De acordo com Freud, todos nós, seja qual for o nosso ambiente circundante, enfrentamos a mesma luta para domesticar nossas pulsões, de modo que não há nenhuma diferença qualitativa entre a saúde e a doença mental. A diferença é de natureza quantitativa. Um acréscimo na quantidade de libido na economia psíquica pode muito bem romper o equilíbrio da saúde e levar a uma neurose. Do mesmo modo, a debilitação do eu por doença orgânica ou por uma demanda particular de sua energia (como no caso, acima descrito, da manutenção de recalques), pode fazer sair à luz neuroses que, de outro modo, teriam permanecido latentes, apesar da predisposição existente.

Importa notar que, a partir de 1916, a noção de predisposição, já não designa somente o que é herdado, constitucional ou inato. Com a introdução das elaborações brevemente descritas acima sobre a pulsão e o recalque, a noção de 'predisposição' ganha e mantém um sentido bem mais amplo, referindo-se tanto a capacidade de resistência do eu relativamente a um gasto maior de energia, quanto à rigidez das fixações libidinais, ambas decorrentes dos desenvolvimentos paralelos e interconectados do eu e da libido. Ou seja, agora, os fatores predisposicionais abarcam simultaneamente o que o indivíduo traz à vida e o que a vida lhe traz. A equação etiológica dos anos 1890 precisava ser profundamente revista, já que não se tratava mais de opor inato e adquirido, buscando identificar onde estaria causa da neurose, mas de pensar o indivíduo como o lugar onde inato e adquirido se tornam praticamente indiscerníveis.

O esquema da equação etiológica da época da teoria do trauma (até 1897) era o seguinte: constituição hereditária + experiências infantis traumáticas e/ou experiências atuais = neurose. Agora, com a complexificação da idéia de predisposição (1916), o esquema transformou-se no seguinte (Figura 1):

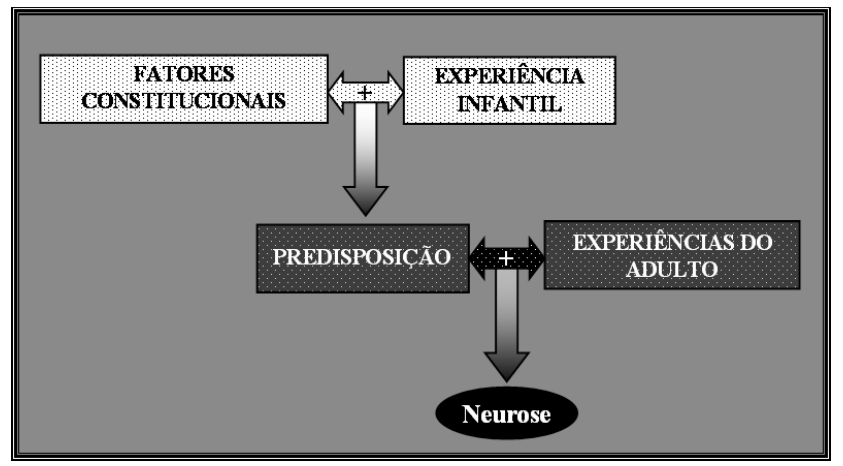

Figura 1. Ilustração das séries complementares propostas por Freud (1916-1917/1996f). 
A predisposição seria o resultado da composição entre o que se traz à vida e o que é adquirido através da experiência na infância, formando a $1^{\text {a }}$ série complementar. À predisposição somam-se as experiências do adulto, formando a $2^{\text {a }}$ série complementar. Em ambas, podem-se encontrar os mesmos casos extremos e as mesmas relações de substituição conforme o princípio da equação etiológica. Por sua vez, a idéia de complementaridade entre as séries revela o quanto a oposição simples entre inato e adquirido tornou-se irrelevante, constituindo o que Freud, já nos anos 1890, identificava como um falso problema.

Dois anos antes de morrer, o metapsicólogo ainda propôs uma nova modificação na equação etiológica (Freud, 1937/1996g) para dar conta do que o conceito de pulsão expressava: o que era identificado por fatores constitucionais (hereditários) seria melhor designado pela noção de intensidade pulsional no momento. Mais ampla, a intensidade pulsional incluiria tanto a intensidade constitucional da pulsão em cada indivíduo, quanto reforços pulsionais que pudessem ocorrer mais tarde na vida por motivos os mais diversos, como por exemplo, a puberdade, o climatério, novos traumas e mesmo novas falências na satisfação pulsional. Vê-se como a dualidade de base herdado/adquirido perde completamente sua importância e fica diluída. Para Freud, nunca foi questão de decidir sobre a causa última, se a natureza do que aconteceu ao indivíduo ou se suas peculiaridades.

\section{Algumas Contribuições das Neurociências}

Uma das mais importantes contribuições da equação etiológica proposta por Freud é o fato de que, além de interações entre o indivíduo e o seu meio externo durante a fase adulta, deve-se também levar em consideração a interação que ocorre durante o desenvolvimento infantil entre aspectos externos e a constituição do indivíduo herdada geneticamente. Talvez uma das primeiras evidências experimentais que mostram a importância das relações sociais durante a infância na modulação da atividade psicológica da vida adulta tenha surgido com Harry Harlow. Trabalhando com macacos Rhesus, durante a década de 60, Harlow descobriu que filhotes de macacos preferem uma mãe artificial feita de pano felpudo ao invés de outra feita de arame, mesmo que seja esta última a disponibilizar a comida a qualquer momento para o filhote. Noutro estudo, Harlow também demonstrou que filhotes criados na presença de suas mães verdadeiras ou de pano não apresentavam qualquer problema de socialização com outros macacos ao atingirem a adolescência, em oposição a outros macacos criados na ausência de suas mães ou com as de arame (Harlow, 1971).

Estas evidências experimentais estavam totalmente de acordo com observações clinicas realizadas por John Bowlby (1940) e que serviram de base para a formulação da sua teoria do apego (Bowlby, 1969). De acordo com esta teoria, toda criança apresenta uma tendência natural de ligação corporal à sua mãe, independentemente da busca alimentar. Este conceito, desenvolvido inicialmente por Bowlby e aprofundado mais tarde por Mary Ainsworth,
Sworth, Blehar, Waters e Wall (1978), levou em consideração as descobertas que estavam sendo realizadas pelos etologistas da época - Karl von Frisch, Konrad Lorenz e Nikolaas Tinbergen (Dewsbury, 2003) - especialmente no que diz respeito à noção da infância como período crítico. Período crítico porque a experiência durante os primeiros anos de vida tem um efeito estruturante no desenvolvimento da criança, em oposição a efeitos circunstanciais da experiência fora deste período. De fato, o período crítico representa um momento em que o sistema nervoso está extremamente sensível aos processos de aprendizagem produtores de alterações permanentes e definitivas em determinadas estruturas neurais (Hubel \& Wiesel, 1970).

Com efeito, já em 1946, observando crianças institucionalizadas em hospitais e orfanatos, René Spitz descreveu vários fenômenos relativos a perturbações somáticas e psicológicas em crianças privadas de suas mães durante os primeiros anos de vida (Spitz \& Wolf, 1946). Em um deles, denominado de Hospitalism: An inquiry into the genesis of psychiatric conditions in early childhood, Spitz (1945) observou que crianças que jamais tiveram contato afetivo com suas mães ou qualquer substituta apresentavam sérios problemas emocionais. Em outra situação, denominada de depressão anaclítica, a criança havia tido contato inicial com a mãe, tendo sido afastada dela em seguida. Neste último caso, os efeitos adversos da privação materna não eram tão graves como no caso do hospitalismo, revelando com isso o benefício de uma relação materna durante o período crítico. $\mathrm{Na}$ verdade, o hospitalismo, pelo fato da criança ter sido afastada da mãe durante o período crítico, tem o poder de produzir várias conseqüências duradouras e mesmo irreversíveis, enquanto a depressão anaclítica pode cessar quando a criança volta a encontrar a mãe (Pinneau, 1955).

Inúmeros estudos vêm mostrando uma clara associação entre adversidades ocorridas na infância, especialmente durante os primeiros meses de vida, e a origem de distúrbios emocionais e cognitivos na idade adulta (Gunnar, 2003; Rutter \& Maughan, 1997; Sanchez, Hearn, Do, Rilling \& Herndon, 1998; Sroufe, Egeland \& Kreutzer, 1990). Por exemplo, experiências traumáticas na infância podem alterar o funcionamento de estruturas neurais importantes para a expressão da atividade emocional, tais como o hipocampo (Brunson, Chen, Avishai-Eliner, \& Baram, 2003), o hipotálamo (Vázquez, 1998) e o complexo amigdalóide (Kaufman, Plotsky, Nemeroff \& Charney, 2000). Respostas do sistema hormonal, controladas através do eixo hipotalâmico-hipofisário-adrenal, também são extremamente sensíveis a manipulações ambientais ocorridas durante a infância (Barr et al., 2004). Finalmente, as relações sociais durante os primeiros anos de vida também produzem al terações no funcionamento de diversos neurotransmissores, tais como a noradrenalina (Clarke et al., 1996) e a serotonina (Gartside, Johnson, Leitch, Troakes, \& Ingram, 2003).

Deve-se notar que estas respostas comportamentais e neurofisiológicas moduladas pela experiência infantil podem não vir a produzir no futuro afecções psicopatológicas. 
Na verdade, existem evidências mostrando que determinadas pessoas são resilientes ${ }^{3}$ a certas condições adversas, mostrando-se capazes de recuperação rápida após terem se defrontado com um evento traumático na idade adulta. Outras pessoas, frente às mesmas condições adversas, tendem a adoecer (Southwick, Vythilingam \& Charney, 2005). Dessa forma, a ocorrência de um evento traumático na infância não implica necessariamente no adoecimento frente a um novo trauma na idade adulta, pois, conforme vimos na equação etiológica e nas séries complementares freudianas, é necessária a concorrência da pré-condição. Nesse sentido, é importante ressaltar que as experiências infantis interagem com a constituição individual, determinando a vulnerabilidade ao adoecimento.

\section{Um Estudo da Interação entre Genótipo e Ambiente em Quadros Depressivos}

Estudos recentes vêm apontando uma grande associação entre genes relacionados ao sistema serotonérgico e a ocorrência de determinados distúrbios de ansiedade e depressão (Lee et al., 2005; Lima, Sougey \& Vallada, 2004; Pezawas et al., 2005). Os alelos do gene que codifica a molécula transportadora da serotonina (SLC6A4), que em seres humanos está localizado no cromossomo 17, podem ser classificados em longos (L) ou curtos (C). O alelo curto deste gene apresenta uma eficiência transcricional bem mais reduzida quando comparada com o alelo longo. Mais ainda, pessoas que possuem uma cópia do alelo curto tendem a apresentar traços de ansiedade relativamente elevados (Schinka, Busch \& Robichaux-Keene, 2004; Sem, Burmeister \& Ghosh, 2004).

Pesquisadores dos Estados Unidos, Inglaterra e Nova Zelândia (Caspi et al., 2003) investigaram a relação entre o gene que codifica o transportador da serotonina e a ocorrência de maus-tratos na infância, na modulação de transtornos depressivos na idade adulta frente a condições adversas. Neste estudo longitudinal, 847 pessoas, acompanhadas desde a idade de 3 até 26 anos, foram divididas em três grupos de acordo com o tipo de alelos a este gene do transporte da serotonina. Um grupo, composto por 147 pessoas $(17 \%)$, apresentava duas cópias do alelo cur to (CC). Outras 265 pessoas (31\%) tinham duas cópias do alelo longo (LL). Finalmente 435 pessoas $(51 \%)$ tinham uma cópia de cada alelo (CL). Além da tipagem, genética, os pesquisadores registraram também o número de eventos estressantes que cada pessoa desta amostra enfrentou entre 21 e 26 anos de idade. Dentre estes eventos estavam 14 itens tais como problemas no ambiente de trabalho, familiares ou econômicos. Aos 26 anos, todas as pessoas foram

${ }^{3}$ Resiliência é um conceito que vem da física para exprimir uma capacidade elástica que al guns corpos apresentam frente a uma força externa. A força armazenada no corpo causa-lhe uma deformação que desaparece assim que a força tensional cessa. Por analogia, resiliência psicológica é a capacidade que uma pessoa tem de não desenvolver uma patologia quando exposta a um evento hostil. Está relacionada com a disposição que o indivíduo apresenta para superar dificuldades impostas por situações adversas. avaliadas com relação a quatro índices diferentes de depressão: (a) auto-registro de eventos depressivos; (b) probabilidade de ocorrência de um evento depressivo maior; (c) probabilidade de pensamento ou tentativa de suicídio e (d) registro de depressão de um informante próximo ou íntimo da pessoa.

A Figura 2 apresenta os resultados de uma regressão múltipla que estima a associação entre o número de eventos estressantes que ocorreram na idade adulta, entre $21 \mathrm{e}$ 26 anos, e quatro indicadores de depressão avaliados na idade de 26 anos em relação aos três grupos divididos de acordo com o genótipo do transportador da serotonina. Os resultados parecem indicar que o número de cópias do alelo curto determina a ocorrência de sintomas depressivos induzidos por eventos estressantes na vida adulta. Pessoas com duas cópias do alelo curto (CC) foram extremamente sensíveis aos eventos estressantes de forma que os sintomas depressivos produzidos por estes eventos foram muito mais intensos em relação aos dois outros grupos que apresentaram uma ou nenhuma cópia deste alelo. Por outro lado, pessoas com uma única cópia do alelo curto (CL) apresentaram sintomas intermediários de depressão frente ao número de eventos estressantes enquanto que pessoas que não possuíam este tipo de alelo foram muito pouco sensíveis a estes eventos estressantes.

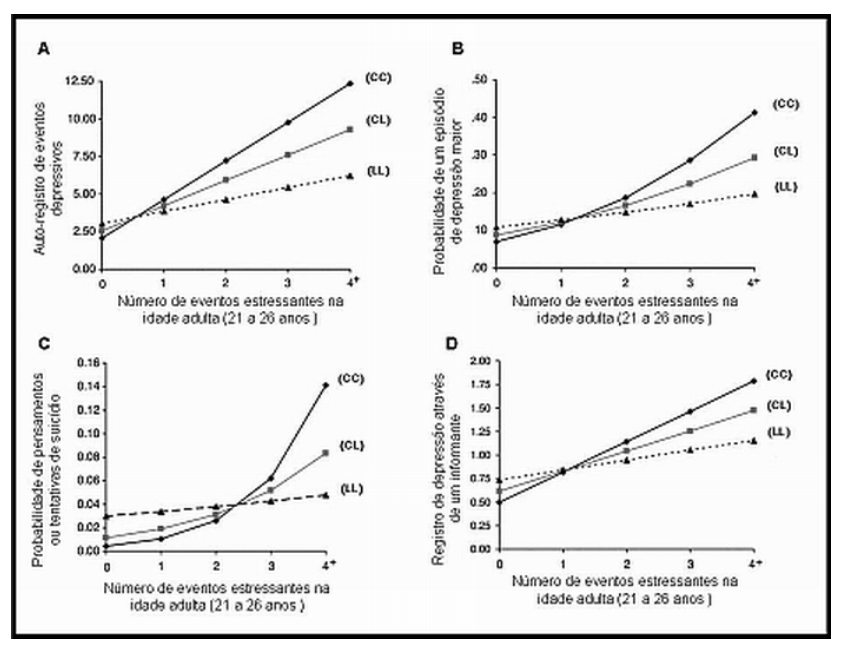

Figura 2. Análise de regressão múltipla para estimar a associação entre o número de eventos estressantes na idade adulta (entre 21 e 28 anos de idade) e diferentes sintomas relacionados com a depressão avaliada na idade de 26 anos de acordo com o tipo de genótipo do transportador da serotonina: CC - duas cópias do alelo de gene curto; LL, duas cópias do alelo de gene longo; CL, uma cópia de cada alelo. No gráfico "A" apresenta-se o número de eventos depressivos relatados pela própria pessoa; em " $B$ " a probabilidade de ocorrência de um evento depressivo maior; em " $C$ " a probabilidade de pensamento ou tentativa de suicídio e em "D” o número de eventos depressivos registrados por um informante próximo ou íntimo da pessoa (adaptado de Caspi et al., 2003).

Os pesquisadores também observaram que o tipo de experiência que estas pessoas tiveram durante a infância interagiu de forma significativa com os seus respectivos genótipos do transportador da serotonina no desenvolvimento de sintomas relacionados à depressão. Nesse sentido, os pesquisadores registraram também eventuais ocor- 
rências de maus tratos que estas pessoas sofreram durante a infância. Estas avaliações foram realizadas através de observações de interação entre mãe-criança quando elas tinham 3 anos de idade, assim como entrevistas com a mãe e outros membros da família em relação a possíveis maus tratos durante os primeiros 11 anos de vida. Calcada nestas avaliações, a amostra foi subdividida em três grandes grupos: um grupo composto por 550 (65\%) pessoas que não sofreram maus tratos; outro grupo com 224 (26\%) pessoas que sofreram maus tratos moderados e um terceiro grupo composto por 73 pessoas (9\%) que sofreram uma quantidade alta de maus tratos.

A Figura 3 apresenta os resultados de uma regressão para estimar a associação entre os maus tratos durante a infância, entre 3 e 11 anos de idade, e a ocorrência de depressão na fase adulta, entre 18 e 26 anos de idade, de acordo com o tipo de genótipo do transportador da serotonina. Os resultados demonstram uma clara interação entre aspectos genéticos e ambientais durante a infância com relação à ocorrência de um evento depressivo na idade adulta. Esta interação revela-se a partir do fato de que o tipo de maus tratos que a pessoa sofreu na infância foi capaz de prever a ocorrência da depressão na fase adulta somente entre aquelas que apresentavam pelo menos uma cópia do alelo curto (CC ou CL), mas não entre homozigóticos que não apresentavam este tipo de alelo (LL).

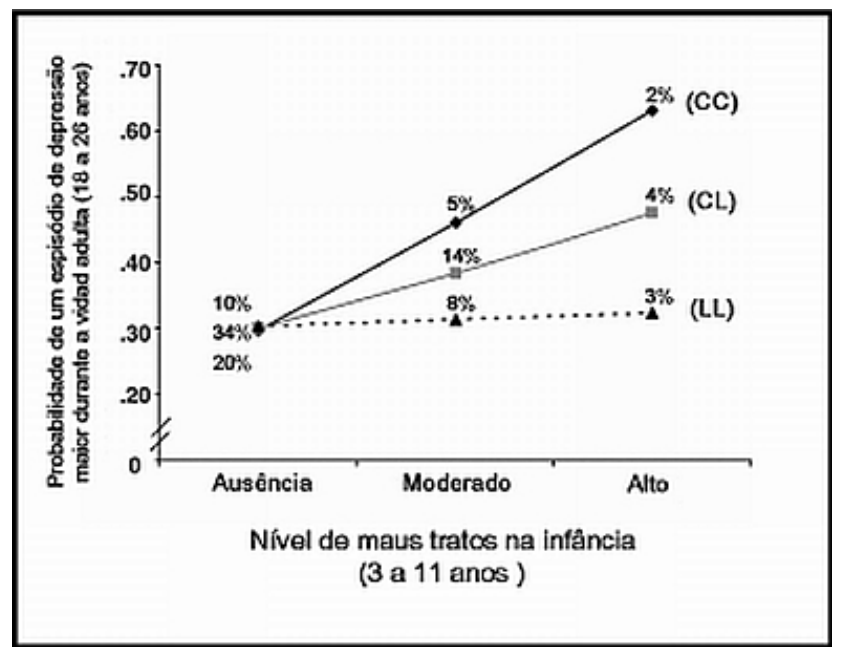

Figura 3. Análise de regressão para estimar a associação entre os maus tratos durante a infância (entre 3 e 11 anos de idade) e a ocorrência de depressão na fase adulta (entre 18 e 26 anos de idade) de acordo com o tipo de genótipo do transportador da serotonina: CC- duas cópias do alelo de gene curto; LL, duas cópias do alelo de gene longo; CL, uma cópia de cada alelo. Os números distribuídos nas três retas indicam a porcentagem de pessoas da amostra em cada uma destas condições (adaptado de Caspi et al., 2003).

Este estudo demonstra que o genótipo deve ser considerado uma pré-condição necessária, mas não suficiente, para a ocorrência de uma determinada afecção psicopatológica. Além dele, é necessário também que determinados eventos traumáticos ocorram durante a infância para que uma determinada disfunção frente a uma condição adversa na vida adulta possa se expressar. Esta interação entre fatores genéticos e ambientais durante a infância pode também ser inferida através da análise de regressão que indicou uma maior probabilidade de ocorrência de um evento depressivo grave em apenas $2 \%$ da amostra, correspondendo exatamente às pessoas que apresentam o genótipo $\mathrm{CC}$ e que sofreram uma alta incidência de maus tratos na infância. Esta incidência de $2 \%$ da amostra está bem próxima de dados epidemiológicos recentes que indicam uma incidência de depressão grave na população em torno de 3\% (Patten \& Lee, 2004).

\section{Um Segundo Estudo sobre a Depressão: A Importância do Apoio Social}

Este mesmo padrão de resultados foi encontrado em outro estudo realizado por um grupo de pesquisadores da Universidade de Yale (Kaufman et al., 2004). Participaram deste estudo 101 crianças com idade variando de 5 a 15 anos de idade. Cinqüenta e sete destas crianças estavam separadas de seus pais nos últimos 6 meses devido a alegações de maus tratos tais como abuso sexual (19\%), violência doméstica (60\%), abuso físico (63\%), maus tratos emocionais $(79 \%)$ e descaso familiar (80\%). As outras 44 crianças serviram de controle sem nenhuma história de maus tratos. O nível de depressão de cada criança foi avaliada através de um teste específico de depressão para crianças.

A Figura 4 apresenta os resultados deste estudo. Como se pode observar, crianças do grupo controle apresentam baixos escores de depressão independentemente do genótipo à molécula transportadora de serotonina. Crianças que receberam maus tratos com genótipos LL ou LC também apresentaram baixos escores no teste de depressão. Entretanto, crianças que sofreram maus tratos e apresentaram um genótipo CC apresentaram altos escores de depressão. Estes resultados replicaram o estudo de Caspi et al. (2003) e confirmam a importância da interação entre fatores genéticos e ambientais na ocorrência de disfunções mentais.

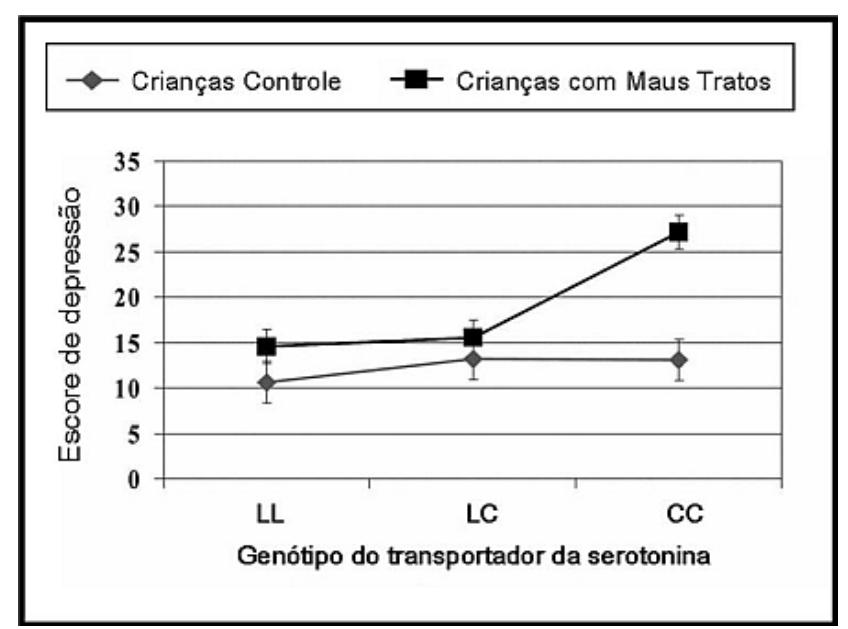

Figura 4. Interação entre o genótipo da molécula transportadora da serotonina e maus tratos na infância nos escores de depressão. 
Este estudo investigou também se a presença de algum tipo de apoio social poderia ter algum efeito sobre o alto nível de depressão entre as crianças predispostas geneticamente e com história de maus tratos. Desta forma, a freqüência com que cada uma das 57 crianças expostas a maus tratos mantinham estas relações sociais com o principal responsável foi também avaliada. Calcado na freqüência do apoio social, as crianças com histórias de maus tratos foram divididas em dois grupos: um grupo composto por crianças que recebiam visitas regulares (uma ou vezes por mês) e outro por crianças que recebiam visitas esporádicas (pelo menos uma visita semestral).

A Figura 5 apresenta o efeito da freqüência de apoio social no escore de depressão em crianças que receberam maus tratos na infância com diferentes genótipos à molécula de transporte da serotonina. Os resultados revelam que as seqüelas negativas produzidas pela predisposição genética à molécula transportadora da serotonina associada aos maus tratos na infância podem ser aliviadas através de presença de um sistema de apoio social à criança.

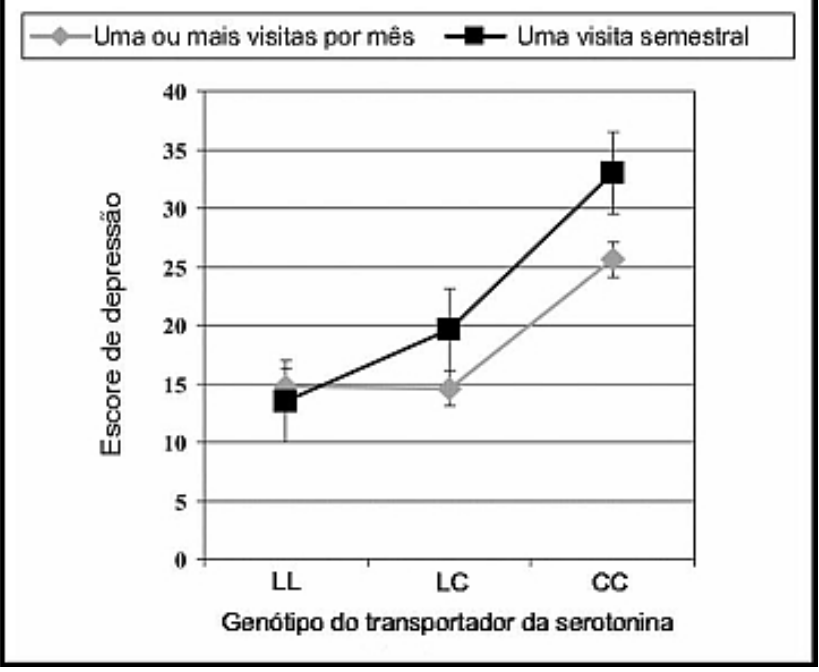

Figura 5. Efeito da freqüência das visitas de uma pessoa responsável por desenvolver algum tipo de apoio social no escore de depressão em crianças que receberam maus tratos na infância com diferentes genótipos à molécula de transporte da serotonina.

\section{A Equação Etiológica como uma Regressão Logística}

Os mesmos dados que forneceram as informações descritas nos gráficos acima (Caspi et al., 2003; Kaufman et al., 2004) permitem a estimação dos parâmetros de uma equação de regressão contendo, como variáveis causais, os termos da equação etiológica definida por Freud (1895/ 1996a, 1916-1917/1996f).

A variável resposta da equação de regressão que estamos propondo é a ocorrência ou não do distúrbio emocional. Chamando de $\mathrm{Y}_{\mathrm{i}} \mathrm{o}$ valor desta variável para o i-ésimo indivíduo, podemos usar a codificação usual, $\mathrm{Y}_{\mathrm{i}}=1$ se o indivíduo desenvolve um transtorno de ansiedade ou de humor e $\mathrm{Y}_{\mathrm{i}}=\mathrm{O}$ no caso contrário. Como esta variável resposta é dicotômica, uma das possibilidades é usar o mode- lo de regressão logística que modela a probabilidade de ocorrer um dos estados possíveis. Vamos chamar $\varphi_{\mathrm{i}}$ a probabilidade de ocorrer o transtorno, ou seja,

$$
\varphi_{\mathrm{i}}=\operatorname{Prob}\left(\mathrm{Y}_{\mathrm{i}}=1\right)
$$

Mais precisamente, a regressão logística é uma regressão linear para uma função não linear desta probabilidade. A função não linear, neste caso, é a função logit, abreviatura usual para o logaritmo da razão de chance. A probabilidade de ocorrer a doença, $\varphi_{i}$, é um número do intervalo entre $\mathrm{o}$ e 1 e fica transformada pela função logit em um número da reta toda, que vamos denotar por outra letra grega, $\eta_{i}$, que é a variável que vamos modelar. Assim,

$$
\eta_{\mathrm{i}}=\log \varphi_{\mathrm{i}} /\left(1-\varphi_{\mathrm{i}}\right)
$$

O primeiro modelo, o mais simples, usa como variáveis explicativas as três causas mencionadas anteriormente, a pré-condição genética, a condição ambiental e a causa precipitante. A pré-condição genética do i-ésimo indivíduo, $G_{i}$, pode ser uma variável ordinal como, por exemplo, nos dois estudos citados (codificada o para quem possui a combinação de alelos LL, 1 para quem possui a combinação LC e 2 para quem possui a combinação CC) mas, pode ser também uma variável contínua advinda de psicodiagnósticos mais precisos. A condição ambiental, $\mathrm{A}_{\mathrm{i}}$, que dá conta das experiências do indivíduo na infância pode ser codificada da mesma maneira (o para quem não sofreu maus-tratos durante a infância, 1 para maus-tratos moderados e 2 para al to). A causa precipitante ou desencadeante, $\mathrm{Di}$, pode ser considerada, num primeiro momento, como dicotômica (o, não atua e 1, atua), ou também como uma variável ordinal, número de eventos estressantes (como em Caspi et al., 2003). O modelo para a variável resposta transformada, $\eta_{i}$, pode ser escrito então,

$$
\eta_{i}=\beta_{0}+\beta_{1} G_{i}+\beta_{2} A_{i}+\beta_{3} D i+\varepsilon_{i},
$$

onde $\varepsilon_{\mathrm{i}}$ é o erro, ou resíduo, da aproximação.

Este modelo teria utilidade para testar a significância do efeito linear das três causas da doença $\left(\beta_{1}, \beta_{2}, \beta_{3}\right)$. O intercepto da reta de regressão pode ser interpretado como sendo relacionado à probabilidade eventual de ocorrência da doença mesmo na ausência das causas disposicionais e precipitantes. Um modelo como este, apropriadamente calibrado para cer ta população, pode servir ainda para prever a probabilidade de ocorrer a distúrbio emocional dadas as características individuais $\left(\mathrm{G}_{\mathrm{i}}, \mathrm{A}_{\mathrm{i}}, \mathrm{D}_{\mathrm{i}}\right)$.

O passo seguinte da modelagem é introduzir o mecanismo de agravamento que a disposição genética e a trajetória do indivíduo na infância imprimem no caso de ocorrerem eventos estressantes. Tal mecanismo pode ser modelado substituindo o efeito puramente linear da causa precipitante, definido pelo termo contendo $\mathrm{D}_{\mathrm{i}}$ na expressão acima, por um termo de interação entre a causa precipitante e a disposição genética potenciada (por exem- 
plo, elevada ao quadrado). Este termo pode ser escrito como o produto $\mathrm{D}_{\mathrm{i}} \mathrm{G}_{\mathrm{i}}^{2}$.

Respectivamente, o mecanismo de agravamento que a variável ambiental imprime quando ocorre a causa precipitante pode ser escrito como $\mathrm{D}_{\mathrm{i}} \mathrm{A}_{\mathrm{i}}{ }^{2}$. Note-se que este termo diz que, na ausência das disposições genéticas (ou ambientais), os eventos estressantes não são suficientes para tornar a ocorrência da doença mais provável.

A equação etiológica sob a forma de regressão logística, incluindo os mecanismos de necessidade das disposições genéticas e ambientais, fica escrita como

$\eta_{i}=\beta_{0}+\beta_{1} G_{i}+\beta_{2} A_{i}+\beta_{3} D_{i} G_{i}^{2}+\beta_{4} D_{i} A_{i}^{2}+\varepsilon_{i}$.

Outro efeito ainda pode ser incorporando à equação etiológica, de certo modo generalizando a formulação original de Freud. Trata-se de uma variável que descreve algum apoio social ou terapêutico. Isto pode ser feito por meio de uma variável categórica que defina a tipologia da terapia, ou por meio de uma variável ordinal que defina a intensidade da terapia. Este último caso foi empregado por Kaufman et al. (2004) que usou uma escala de cinco pontos para medir a freqüência com que as crianças mantinham relações sociais com seu responsável (ver Figura 5). Denotando a variável de apoio terapêutico para o i-ésimo indivíduo por Ti a equação se escreve:

$\eta_{i}=\beta_{0}+\beta_{1} G_{i}+\beta_{2} A_{i}+\beta_{3} D_{i} G_{i}^{2}+\beta_{4} D_{i} A_{i}^{2}+\beta_{5} T_{i}+\varepsilon_{i}$

A utilidade deste modelo pode ser resumida a dois pontos principais. Primeiro, ele permite a verificação empírica das relações de causalidade definidas a priori pelas considerações teóricas. Os vários efeitos, representados pelos coeficientes $\beta$ 's da equação, podem ser testados por sua significância estatística. Isso dá ao pesquisador uma poderosa ferramenta para avaliar sua teoria. Segundo, o modelo bem calibrado pode servir como instrumento importante para avaliar o risco do transtorno nos indivíduos e apontar eventuais ações de apoio social e terapêutico.

\section{Predisposição e Acaso: Uma Conclusão}

Os resultados dos estudos apresentados acima expressam certa confirmação da proposta freudiana, elaborada a partir de suas observações clínicas, segundo a qual a etiologia dos transtornos emocionais está relacionada a uma conjugação entre disposições inatas e interações com o meio ambiente que, por sua vez, podem atuar diferentemente em dois momentos: durante os primeiros anos de vida, ou o chamado período crítico, e na idade adulta. No período crítico, o ambiente pode ser entendido como estruturante, marcando profundamente e moldando a orga-nização do sistema nervoso e, conseqüentemente, a atividade mental do indivíduo. Este conceito de período crítico está plenamente de acordo com o conceito freudiano de séries complementares. Segundo esta hipótese, a conjugação entre os fatores constituicionais e as experiências infantis compõe a predisposição do indivíduo que indica sua maior ou menor tendência a adoecer psiquicamente. Fora do período crítico, o ambiente tem um efeito disparador ou desencadeante, ou seja, as experiências traumáticas na idade adulta são capazes de desencadear o adoecimento psíquico de acordo com a predisposição singular de cada um.

Contudo, ainda resta uma questão relativa à forma específica da patologia psíquica que se expressa na idade adulta. O que determina a eclosão de uma síndrome do pânico, um transtorno de ansiedade generalizado, um transtorno obsessivo-compulsivo ou uma depressão? Em termos psicanalíticos, a pergunta é sobre a escolha da neurose. A teoria da sedução proposta por Freud foi uma tentativa de responder a estas perguntas, rapidamente abandonada, embora a ênfase na importância das experiências vividas na infância para a determinação da forma posterior do sintoma se tenha mantido. Outra tentativa de resposta é a hipótese de que padrões genéticos determinam a maior ou menor produção de certos neurotransmissores associados a circuitos neurais específicos (por ex., circuito neural responsável por reações de defesa) que, por sua vez, podem participar de certas disfunções emocionais (por ex., transtorno de ansiedade generalizada). Da mesma forma, um mesmo neurotransmissor (por ex., a serotonina) pode atuar em diferentes circuitos neurais, participando de diferentes transtornos emocionais (por ex., depressão e síndrome do pânico).

A noção de resiliência, bastante próxima da idéia freudiana de uma capacidade de resistência diferenciada para cada eu singular, aparece, assim, diretamente vinculada à noção de predisposição. Uma predisposição resiliente definiria, portanto, indivíduos que, mesmo quando expostos a situações de adversidade, não desenvolvem uma patologia psíquica, mas, ao contrário, apresentam uma capacidade de superar as dificuldades impostas pelo meio. Em termos freudianos, a resiliência ou a robustez do eu, bem como as fixações libidinais, parecem constituir-se ao longo do período crítico, como fruto da interação entre a constituição e as experiências infantis.

Esta idéia de vulnerabilidade ou de variação na resiliência evidencia a característica plástica do nosso sistema nervoso, como demonstram os resultados dos estudos envolvendo a presença de algum tipo de apoio social para crianças predispostas geneticamente à depressão e com história de maus-tratos. Embora não existam dados disponíveis com relação à psicoterapia, podemos levantar a hipótese de que, além dos insights que ela promove, sua eficácia reside justamente no apoio social por ela oferecida. Apoio capaz de aliviar significativamente as seqüelas negativas produzidas pela predisposição genética à molécula transportadora da serotonina associada aos maus-tratos na infância.

Desta forma, se a predisposição expressa uma maior vulnerabilidade ao adoecimento mental, isso não significa uma condenação ao sofrimento eterno. É necessário que determinados eventos traumáticos ocorram ao longo do desenvolvimento ontogenético do indivíduo. Por outro lado, a plasticidade de nosso sistema nervoso permite atenuar ou mesmo reverter certos quadros patológicos. Mais 
Winograd, M., Coimbra, C. A. Q. \& Ladeira-Fernandez, J. (2007). O que se Traz para a Vida e o que a Vida nos Traz: Uma Análise da Equação Etiológica Proposta por Freud à Luz das Neurociências

ou menos resilientes, somos sempre o resultado dos bons e maus encontros entre nossa constituição e o ambiente no qual vivemos.

\section{Referências}

Ainsworth, M., Sworth, M., Blehar, M., Waters, E., \& Wall, S. (1978). Patterns of attachment: A psychological study of the strange situation. Hillsdale, NJ: Lawrence Erlbaum.

Barr, C. S., Newman, T. K., Shannon, C., Parker, C., Dvoskin, R. L., Becker, M. L., Schwandt, M., Champoux, M., Lesch, K. P., Goldman, D., Suomi, S. J., \& Higley, J. D. (2004). Rearing condition and rh5-HTTLPR interact to influence limbichypothalamic-pituitary-adrenal axis response to stress in infant macaques. Biological Psychiatry, 55, 733-738.

Bowlby, J. (1940). The influence of early environment in the development of neurosis and neurotic character. International Journal of Psychoanalysis, 21, 1-25

Bowlby, J. (1969). Attachement and loss: Vol. 1. Attachment. New York: Basic Books.

Brunson, K. L., Chen, Y., Avishai-Eliner, S., \& Baram, T. Z. (2003). Stress and the developing hippocampus: A double-edged sword? Molecular Neurobiology, 27, 121-136.

Caspi, A., Sugden, K., Moffitt, T. E., Taylor, A., Craig, I. W., Harrington, H. L., McClay, J., Mill, J., Martin, J., Braithwaite, A., \& Poulton R. (2003). Influence of life stress on depression: Moderation by a polymorphism in the 5-HTT gene. Science, 301, 386-389

Clarke, A. S., Hedeker, D. R., Ebert, M. H., Schmidt, D. E., McKinney, W. T., Kraemer, G. W. (1996). Rearing experience and biogenic amine activity in infant rhesus monkeys. Biological Psychiatry, 40, 338-352.

Dewsbury, A. A. (2003). The 1973 Nobel Prize for Physiology or Medicine: Recognition for behavioral science? American Psychologist, 58, 747-52.

Fisher, R. A. (1918). The correlation between relatives on the supposition of Mendelian Inheritance. Philosophical Transactions of the Royal Society of Edinburgh, 52, 399-433.

Freud, S. (1996a). A propósito de las críticas a la 'neurosis de angustia'. In Sigmund Freud: Vol. 3. Obras Completas. Buenos Aires, Argentina: Amorrortu. (Original publicado em 1895)

Freud, S. (1996b). La herencia y la etiologia de las neurosis. In Sigmund Freud: Vol. 3. Obras Completas. Buenos Aires, Argentina: Amorrortu. (Original publicado em 1896)

Freud, S. (1996c). Carta a Fliess de 21/09/1897. In Sigmund Freud: Vol. 1. Obras Completas. Buenos Aires, Argentina: Amorrortu. (Original publicado em 1897)

Freud, S. (1996d). La pulsión. In Sigmund Freud: Vol. 14. Obras Completas. Buenos Aires, Argentina: Amorrortu. (Original publicado em 1915)

Freud, S. (1996e). La Repressión. In Sigmund Freud: Vol. 14. Obras Completas. Buenos Aires, Argentina: Amorrortu. (Original publicado em 1915)

Freud, S.(1996f). 22 a . Conferencia: algunas perspetivas sobre el desarrollo y la regresión. Conferencias de introducción al psicoanálisis. In Sigmund Freud: Vol. 15. Obras Completas. Buenos Aires, Argentina: Amorrortu. (Original publicado em 1916-1917)

Freud, S. (1996g). Análisis terminable y interminable. In Sigmund Freud: Vol. 23. Obras Completas. Buenos Aires, Argentina: Amorrortu. (Original publicado em 1937)
Gartside, S. E., Johnson, D. A., Leitch, M. M., Troakes, C., \& Ingram, C. D. (2003). Early life adversity programs changes in central 5-HT neuronal function in adulthood. European Journal of Neuroscience, 17, 2401-2408.

Gunnar, M. R. (2003). Integrating neuroscience and psychological approaches in the study of early experiences. Annals of the New York Academy of Science, 1008, 238-47.

Harlow, H. F. (1971). Learning to love. San Francisco, CA: Albion.

Hubel, D. H., \& Wiesel, T. N. (1970). The period of susceptibility to the physiological effects of unilateral eye closure in kittens. Journal of Physiology, 206, 419-436.

Kaufman, J., Plotsky, P. M., Nemeroff, C. B., \& Charney, D. S. (2000). Effects of early adverse experiences on brain structure and function: Clinical implications. Biological Psychiatry, 48, $778-790$

Kaufman, J., Yang, B. Z., Douglas-Palumberi, H., Houshyar, S., Lipschitz, D., Krystal, J. H., \& Gelernter, J. (2004). Social supports and serotonin transporter gene moderate depression in maltreated children. Proceedings of the National Academy of Science USA, 101, 17316-17321.

Lee, H. J., Lee, M. S., Kang, R. H., Kim, H., Kim, S. D., Kee, B. S., Kim, Y. H., Kim, Y. K., Kim, J. B., Yeon, B. K., Oh, K. S., Oh, B. H., Yoon, J. S., Lee, C., Jung, H. Y., Chee, I. S., \& Paik, I. H. (2005). Influence of the serotonin transporter promoter gene polymorphism on susceptibility to posttraumatic stress disorder. Depression \& Anxiety, 21, 135-139.

Lima, I. V. M., Sougey, E. B., \& Vallada, H. P. (2004). Genética dos transtornos afetivos. Psiquiatria Clínica, 31, 1, 34-39.

Patten, S. B., \& Lee, R. C. (2004). Towards a dynamic description of major depression epidemiology. Epidemiology Psychiatry Society, 13, 21-8.

Pezawas, L., Meyer-Lindenberg, A., Drabant, E. M., Verchinski, B. A., Munoz, K. E., Kolachana, B. S., Egan, M. F., Mattay, V. S., Hariri, A. R., \& Weinberger, D. R. (2005). 5-HTTLPR polymorphism impacts human cingulate-amygdala interactions: A genetic susceptibility mechanism for depression. Nature Neuroscience, 8, 828-834.

Pinneau, R. S. (1955). The infantile disorders of hospitalism and anaclitic depression. Psychological Bulletin, 52, 429-52.

Rutter, M., \& Maughan, B. (1997). Psychosocial adversities in childhood and adult psychopathology. Journal of Personality Disorders, 11, 4-18,

Sanchez, M. M., Hearn, E. F., Do, D., Rilling, J. K., \& Herndon, J. G. (1998). Differential rearing affects corpus callosum size and cognitive function of rhesus monkeys. Brain Research, 812, $38-49$.

Schinka, J. A., Busch, R. M., \& Robichaux-Keene, N. (2004). A meta-analysis of the association between the serotonin transporter gene polymorphism (5-HTTLPR) and trait anxiety. Molecular Psychiatry, 9, 197-202.

Sen, S., Burmeister, M., \& Ghosh, D. (2004). Meta-analysis of the association between a serotonin transporter promoter polymorphism (5-HTTLPR) and anxiety-related personality traits. American Journal of Medical Genetic B Neuropsychiatric Genetic, 127, 85-89.

Southwick, S. M., Vythilingam, M., \& Charney, D. S. (2005).The psychobiology of depression and resilience: Implications for prevention and treatment. Annual Review of Clinical Psychology, 1, 255-291.

Sulloway, F. J. (1979). Freud, biologist of the mind: Beyond the psychoanalytic legend. Cambridge, MA: Harvard University Press 
Spitz, R. (1945). Hospitalism: An inquiry into the genesis of psychiatric conditions in early childhood. The Psychoanalytic Study of the Child, 1, 53-74.

Spitz, R. L., \& Wolf, K. M. (1946). Anaclitic depression. The Psychoanalytic Study of the Child, 2, 313-342.

Sroufe, L. A, Egeland, B., \& Kreutzer, T. (1990). The fate of early experience following developmental change: Longitudinal approaches to individual adaptation in childhood. Child Developmental, 61, 1363-1373.

Vázquez, D. M. (1998). Stress and the developing limbichypothalamic-pituitary-adrenal axis. Psychoneuroendocrinology, 23, 663-700.

Watson, J. D., \& Crick, F. H. C. (1953). Molecular structure of nucleic acids. Nature, 171, 737-738.

Yates, F., \& Mather, K. (1963). Ronald Aylmer Fisher. Biographical memoirs of fellows of the Royal Society of London, 9, 91-120. 